\title{
The beet armyworm in floricultural crops
}

Harvey A. Yoshida $\square$ Michael P. Parrella

\section{Common in field and vegetable crops, the beet armyworm has invaded flower crops. It's hard to control with insecticides and can quickly build resistance. Microbial insecticides may be an effective alternative.}

\begin{abstract}
$\mathbf{T}$ of numerous field and vegetable crops. Recently, this insect, Spodoptera exigua (Hubner), has also become the major lepidopterous pest in floricultural crops, causing serious losses in chrysanthemums, carnations, roses, gypsophila, geraniums, and many species of bedding plants. Chrysanthemum has been particularly hard hit with estimates of greater than 30 percent crop loss in San Diego County during 1984 . This loss occurred despite regular weekly applications of broad-spectrum insecticides. The development of insecticide resistance and the compromising of successful biological control of the leafminer, Liriomyza trifolii (Burgess), (California Agriculture, January-February 1986) by these insecticide applications were our primary concerns.

We therefore conducted studies to determine the biology of beet armyworm on ornamentals such as chrysanthemum and to examine the possibility that this species has developed resistance to commonly used insecticides. Insecticides potentially compatible with parasites and less prone to cross-resistance in $L$. trifolii were evaluated for beet armyworm control.
\end{abstract}

\section{Biology}

A great deal is known about selected biological aspects of the beet armyworm but little information is available concerning this pest specifically on ornamentals. We were especially interested in finding out which aspects of the beet armyworm's biology contributed to the difficulty of controlling it in the greenhouse. In field studies conducted from January to December 1985 , weekly visits were made to chrysanthemum and carnation greenhouses in San Diego County to observe the adult flight activity of beet armyworm, egg laying, larval behavior, and pupation.

Through these observations certain behavioral traits became evident. Eggs are generally laid on the undersurfaces of leaves; however, egg masses have occa- sionally been seen on the upper surfaces of some plants, carnation, for example. Egg masses are typically covered with a mat of scales by the female. Presumably, this behavior could prevent desiccation of the eggs and reduce parasitization and exposure to insecticides.

Behavior of beet armyworm larvae also appears to reduce the effectiveness of chemical control. Earlier larval stages (first to third instars) prefer to feed in the plant's growing tip regions. In addition, the younger larvae typically web several leaves together, forming an enclosure that protects them from insecticide sprays. Larvae have also been observed feeding within developing flower buds of some crops, which appears to provide a defense against insecticides and natural enemies

These behaviors are critical in protecting the earlier instars, which are generally more susceptible to insecticides. Older larvae appear to be less selective in their diet and are not restricted to the younger plant tissues. Tolerance of older larvae to
Beet armyworm damage to flower bud

insecticides is generally greater than that of younger larvae, possibly because of an inherently higher content of detoxifying enzymes.

Toward the late part of the last instar, larvae leave the plant in search of a pupation site. The pupal stage is passed in an earthen cell about an inch beneath the soil surface. This behavior again allows the beet armyworm to isolate itself from natural enemies and insecticide sprays.

Although larvae are responsible for direct damage to plants, information about adult activity can enhance the effectiveness of control strategies against the beet armyworm. We monitored adult flight activity using delta traps baited with a synthetic beet armyworm pheromone at a commercial carnation greenhouse in Encinitas, California.

Flight activity appears to be highest during warm, late summer months (August-September) and decreases as temperatures drop (fig.1). This pattern con-

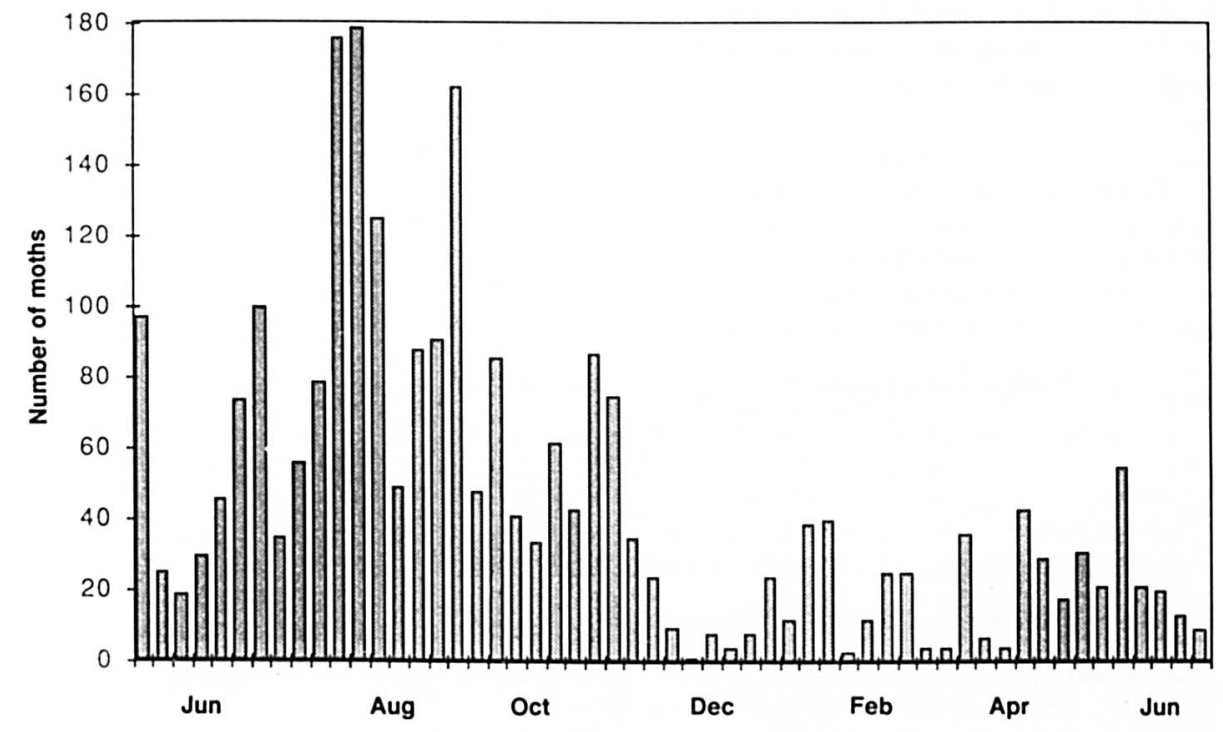

Fig. 1. BAW fluctuations in a carnation greenhouse 


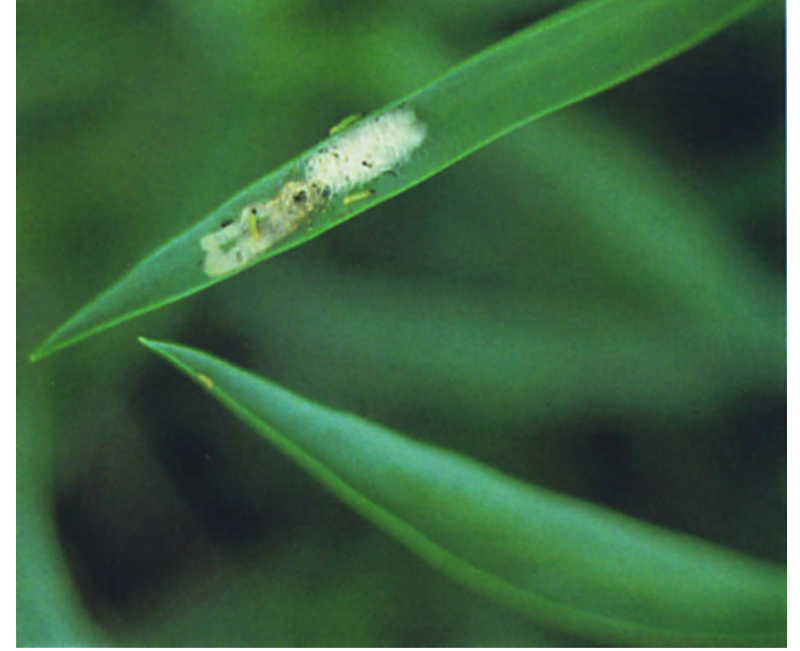

Beet armyworm egg mass and first-instar larvae on carnation leaf

firms field observations that infestation levels are highest during the summer and very low during winter and spring.

\section{Resistance studies}

Field-collected larvae from selected ornamental plantings in California and Florida were brought to the laboratory and placed on an artificial diet. The firstgeneration offspring of these larvae were used in resistance bioassays. We chose methomyl (Lannate) as the test insecticide, because it is commonly used by growers and development of resistance by beet armyworm was suspected.

A microapplicator was used to apply technical methomyl in acetone $(1 \mu \mathrm{L} /$ larva) to third-instar beet armyworm larvae of approximately the same weight. Larvae were returned to artificial diet and mortality determined after 24 hours. After testing a range of doses, we selected five doses that provided between 10 and 90 percent mortality. There were five replicates per dose with 15 and 20 larvae per replicate. Data were analyzed using standard probit analysis techniques.

Three beet armyworm strains were assayed: LB, GR, and FL. The LB strain had been reared in the laboratory on artificial diet for about two years after having been collected from numerous host plants in southern California. The GR and FL strains were collected from roses in Santa Barbara, California, and chrysanthemum in Alva, Florida, respectively. The three strains varied in their previous exposure to insecticides: the $L B$ strain had no exposure for approximately two years; the GR and FL strains had received "moderate" and "heavy" exposures, respectively.

As suspected, the LB strain showed high susceptibility to Lannate, yielding the lowest $\mathrm{LD}_{50}$ (the dose required to obtain 50 percent mortality) at $2.77 \mathrm{~g} / \mu \mathrm{L}$ (table 1). The FL strain produced an $\mathrm{LD}_{50}$ value of $28.43 \mathrm{~g} / \mu \mathrm{L}$, about a 10 -fold difference in resistance. The GR strain yielded intermediate results with an $\mathrm{LD}_{50}$ of $4.11 \mathrm{~g} / \mu \mathrm{L}$ and a resistance ratio of about 1.5 .

These results reflect the insecticide exposure histories of the three strains. Since the LB strain had been isolated in the laboratory for two years, very low levels of resistance, if any, were expected. Both the GR and FL strains had previously experienced moderate to heavy exposure to several insecticides including Lannate. In fact, the use of Lannate has been terminated at this site in Florida because of its ineffectiveness in control of the beet armyworm. The higher $L_{50}$ value indicates that resistance may still be increasing in the FL strain. Resistance development in the GR strain appears doubtful at this time. If similar insecticide use patterns are followed in California as in Florida, however, development of resistance to Lannate in the beet armyworm is likely.

\section{Insecticide efficacy}

As previously stated, the use of conventional broad-spectrum insecticides to control the beet armyworm may jeopardize the success of existing biological control programs in greenhouses. However, "selective" microbial insecticides may offer great potential for the control of the beet armyworm while preserving important natural enemies. We evaluated three Bacillus thuringiensis (BT) compounds (Dipel, Javelin, and Thuricide) along with Thuringiensin for their effectiveness against the beet armyworm under labora- tory conditions. The active ingredient of the BT compounds used in this study is delta-endotoxin, which is specific against lepidopterous pests and therefore compatible with natural enemies occurring in greenhouses. Thuringiensin, a chemical by-product from a particular BT strain, however, contains beta-exotoxin, and its effects on natural enemies are presently not known.

Two-week-old chrysanthemum plants (cv 'Hurricane') were sprayed with the insecticides until runoff, and five secondinstar beet armyworm larvae were confined to each plant and held at $80^{\circ} \mathrm{F}$. A mortality check was made after 48 hours and all surviving larvae were placed on artificial diet at $80^{\circ} \mathrm{F}$. Larvae were monitored daily until pupation.

The insecticide treatments did not produce any significant differences after 48 hours (table 2). After seven days, however, the Dipel/Thuringiensin and the Thuringiensin treatments yielded 24 and 42 percent mortality, respectively. Although this proved to be significantly different from the control, this level of mortality would not be acceptable in most commercial operations.

Correlating effectiveness of microbial insecticides with mortality alone can be misleading, however. Pathogens may often induce debilitating effects in their hosts that can provide adequate levels of control without high mortality. This appears to have been the case with the Thuringiensin-treated larvae. After seven days, 97 and 100 percent of the larvae in the Dipel/Thuringiensin and Thuringensin treatments, respectively, had still not molted and remained in the second instar. By comparison, 98 percent of the larvae in the control treatment progressed to the fourth instar. It appears that larvae exposed to Thuringiensin failed to develop normally. Feeding was also suppressed, resulting in a lower level of damage to the test plants.

\section{Conclusions}

Beet armyworm has acquired the reputation of being very difficult to control. Field observations have revealed certain adult and larval behaviors that may contribute to this problem.

\begin{tabular}{|c|c|c|c|}
\hline \multirow[b]{2}{*}{ Statistics } & \multicolumn{3}{|c|}{ Strain } \\
\hline & LB & GR & FL \\
\hline $\mathrm{LD}_{50}(\mathrm{~g} / \mu \mathrm{L})$ & 2.77 & 4.13 & 28.43 \\
\hline $95 \%$ confidence limits & $1.49-5.13$ & $2.22-7.75$ & $10.51-68.24$ \\
\hline $\mathrm{LD}_{90}(g / \mu \mathrm{L})$ & 34.41 & 43.41 & 344.42 \\
\hline $95 \%$ confidence limits & $13.69-89.27$ & $9.65-215.46$ & $39.01-4559.29$ \\
\hline Slope & 1.17 & 1.25 & 1.18 \\
\hline Standard error & 0.13 & 0.22 & 0.40 \\
\hline Number & 1201 & 840 & 716 \\
\hline Resistance ratio ${ }^{*}$ & 1.00 & 1.49 & 10.26 \\
\hline
\end{tabular}

TABLE 2. Effect of selected insecticides on second-instar beet armyworm

'LD 50 of test strain per LD 50 of most susceptible strain (LB)

\begin{tabular}{l} 
TABLE 2. Effect of selected insecticides on second-instar beet armyworm \\
\hline \hline
\end{tabular}


One aspect of beet armyworm behavior that can be exploited to curb infestations is adult flight activity. Pheromone traps, an effective way to monitor beet armyworm populations, have shown that population density fluctuates with seasonal temperature patterns; infestations are more prevalent during the summer, when temperatures are high. Pheromone traps may also provide early warning of an infestation, preventing an outbreak if control is successful.

Laboratory assays indicated that the beet armyworm can develop resistance to Lannate. A Florida (FL) strain was shown to be moderately resistant to Lannate, and evidence indicates that resistance may still be increasing. Resistance to Lannate in the California strain (GR), however, could not be detected. Several steps can be taken to suppress the development of resistance: (1) insecticide rotation, (2) localized treatment of infestations, and (3) use of microbial agents.

There are presently several insecticides registered for use against the beet armyworm on ornamentals in California, including Dursban, Lannate, and Pounce. Each may be incorporated into the present chemical control program and used on a rotational basis. A rotation scheme of this nature will prevent the beet armyworm from being repeatedly exposed to a single insecticide, a situation conducive to the rapid development of insecticide resistance.

Another measure that may deter development of resistance is localized treatment of infestations. Beet armyworm infestations are often clumped or aggregated, apparently because of the egg-laying patterns of the adult female. Treatments confined to these areas reduce the amount of insecticide needed and preserve natural enemies, as well as reducing resistance development.

Bacillus thuringiensis compounds hold great potential for control of lepidopterous pests. In addition to the conventional broad-spectrum insecticides used against the beet armyworm, the inclusion of BT compounds in a control program may delay the occurrence of resistance. BT has a different mode of action, which may help to decrease the probability of resistance development. Furthermore, BT is virtually nontoxic to mammals, very compatible with most natural enemies, and relatively harmless to plants. BT is registered for this use on ornamentals. Thuringiensin, however, is not currently registered.

Harvey A. Yoshida is a graduate student, and $\overline{M i}$ chael P. Parrella is Associate Professor of Entomology, Department of Entomology, University of California, Riverside. This research was supported, in part, by the American Florists Endowment, The Fred C. Gloeckner Foundation, the California Association of Nurserymen, and Statewide Critical Applied Research Funds from UC Riverside. The authors thank Dr. Joe Begley, Yoder Brothers, Alva, Florida, for supplying beet armyworm.

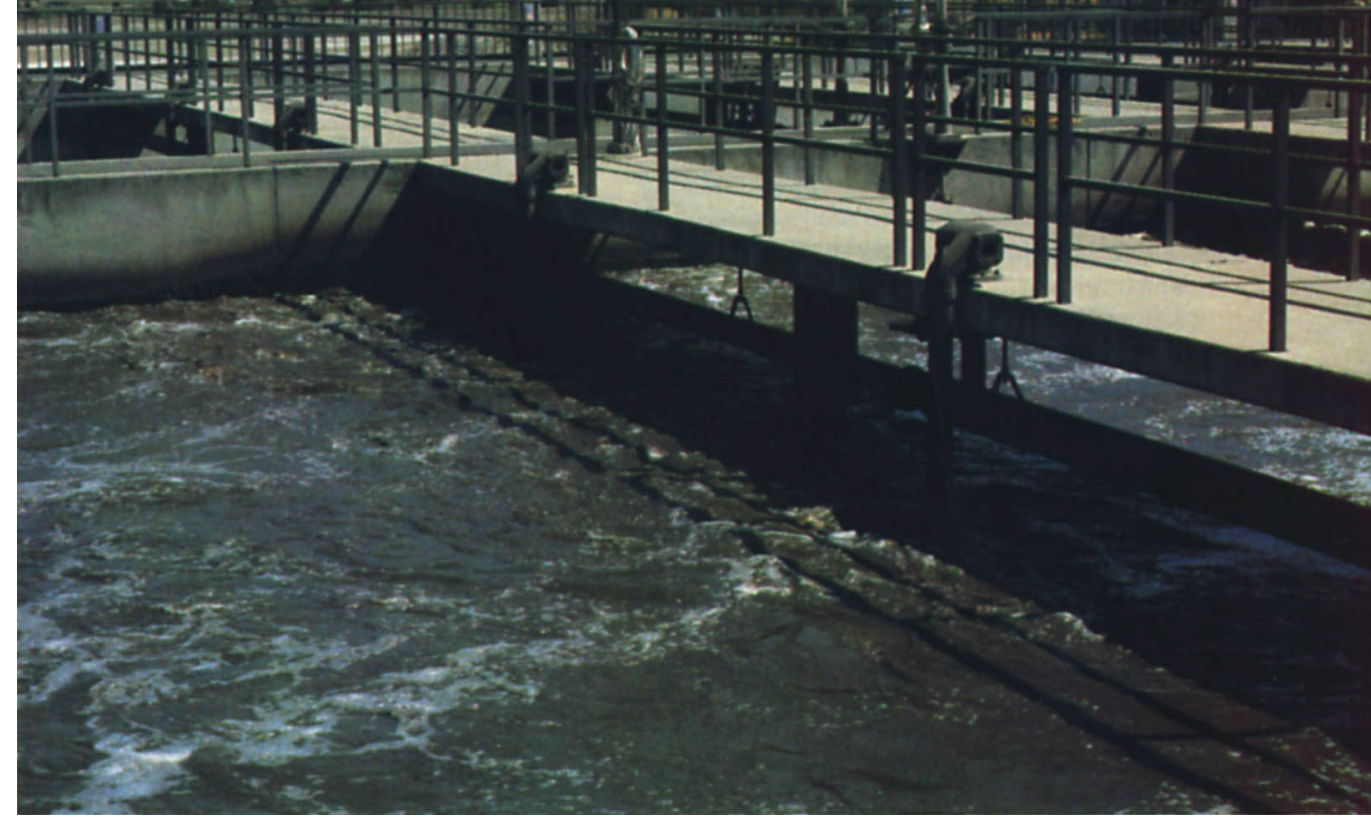

Activated sludge, secondary treatment of municipal wastewater.

\section{Using reclaimed municipal wastewater for irrigation}

Takashi Asano $\square$ G. Stuart Pettygrove

\section{The risks are proportional to the degree of human contact and the adequacy and reliability of treatment.}

Land application of municipal wastewater is a well-established practice in many arid and semiarid regions of the world. In some regions, 70 to 85 percent of such water is used for agricultural and landscape irrigation. As demand for water increases in this country, irrigation with reclaimed municipal wastewater has become a logical and important component of total water resource planning and development.

In California, about 220,000 acre-feet of municipal wastewater from 240 cities and towns are used each year, principally for agricultural and landscape irrigation. In addition, about 610,000 acre-feet per year of treated wastewater is incidentally reused after it is discharged and enters surface or ground waters. Over half of the intentionally reclaimed municipal wastewater ( 57 percent) is used to irrigate fodder, fiber, and seed crops, a use not requiring a high degree of treatment. About 7 percent is used to irrigate orchard, vine, and other food crops. Irrigation of golf courses and landscape areas makes use of about 14 percent of reclaimed wastewater each year, and these uses are increasing.

There are several reasons for the growing use of reclaimed municipal wastewater, including: (1) the lack of fresh water at a competitive price; (2) the potential use of plant nutrients in reclaimed municipal wastewater; (3) the availability of high-quality effluents; (4) a need to establish comprehensive water resource planning, including water conservation and reuse; and (5) the avoidance of more stringent water pollution control requirements, including advanced wastewater treatment facilities at municipalities.

Although irrigation with municipal wastewater is in itself an effective form of wastewater treatment, some additional treatment must be made before such water can be used for agricultural or landscape irrigation. The degree of treatment is an important factor in the planning, design, and management of wastewater irrigation systems. Preapplication treatment is necessary to protect public health, to prevent nuisance conditions during application and storage, and to prevent damage to crops, soils, and groundwater.

\section{Reclaimed water quality}

The quality of reclaimed water depends to a great extent on the quality of the municipal water supply, the nature of the wastes added during use, and the de- 